The Open Respiratory Medicine
Crossmark
Cournal

RESEARCH ARTICLE

\title{
Determinants of Restrictive Spirometric Pattern in a Sub-Saharan Urban Setting: A Cross-sectional Population-based Study
}

Eric Walter Pefura-Yone ${ }^{1,2,}$, Adamou Dodo Balkissou ${ }^{1,2}$ and Andre Pascal Kengne ${ }^{3,4}$

${ }^{\prime}$ Department of Internal Medicine and Specialties, Faculty of Medicine and Biomedical Sciences, University of Yaounde I, Yaounde, Cameroon

${ }^{2}$ Pneumology Service, Yaounde Jamot Hospital, Yaounde, Cameroon

${ }^{3}$ South African Medical Research Council, Cape Town, South Africa

${ }^{4}$ University of Cape Town, Cape Town, South Africa, Cape Town, South Africa

Received: September 08, 2016

Revised: November 21, 2016

Accepted: November 21, 2016

\section{Abstract:}

Background

Restrictive spirometric pattern is a risk factor for all-cause and cause-specific mortality.

\section{Objective}

We assessed the prevalence of restrictive pattern and investigated its determinants in a major sub-Saharan Africa city.

\section{Methods}

Participants were adults ( $\geq 19$ years) who took part in a population-based survey in Yaounde (Cameroon) between December 2013 and April 2014. Restrictive pattern was based on a FVC below the lower limit of the normal (LLN) and a ratio forced expiratory volume in one second (FEV1)/FVC $\geq$ LLN (LLN-based restrictive pattern) or a FVC $<80 \%$ and FEV1/FVC $\geq$ LLN (fixed cut-off based restrictive pattern). Determinants were investigated by logistic regressions.

\section{Results}

In all, 1003 participants [514 (51.2\%) women] with a mean age of 33.7 years were included. The prevalence of restrictive pattern was 18.8\% (95\%CI: 16.6-21.2) based on LLN and 15.0\% (13.0-17.2) based on fixed cut-off. LLN-based restrictive pattern was mild in $148(78.3 \%)$ subjects, moderate in $35(18.5 \%)$ and severe in $6(3.2 \%)$. Determinants of LLN-based restrictive pattern were age $\geq 60$ years [adjusted odds ratio $2.90(95 \% \mathrm{CI} 1.46-5.77), \mathrm{p}=0.002)$, history of pulmonary tuberculosis [3.81(1.42-10.20), $\mathrm{p}=0.008$ ], prevalent heart diseases [3.81 (1.20-12.12), $\mathrm{p}=0.024]$ and underweight [5.15(1.30-20.39), $\mathrm{p}=0.020]$. Determinants were largely similar with slightly different effect sizes for fixed cut-off based restrictive pattern.

\section{Conclusion}

Restrictive pattern was very frequent in this city.

\section{Clinical implications}

These results enhance the needs to increase the efforts to prevent and control tuberculosis, cardiovascular diseases and underweight in this setting.

Keywords: Africa, Cameroon, Low forced vital capacity, Prevalence, Pulmonary restriction, Restrictive lung disease.

\footnotetext{
"Address correspondence to this author at the Department of Internal Medicine and Specialties, Faculty of Medicine and Biomedical Sciences, University of Yaounde I, Yaounde, Cameroon Tel: (237)696539726; Fax: (237)222203165; Email: pefura2002@yahoo.fr
} 


\section{INTRODUCTION}

Vital capacity (VC) and forced expiratory volume in one second (FEV1) are the commonly used ventilatory parameters in functional evaluation and assessment of severity of respiratory diseases [1]. Studies have reported a relationship between these two parameters and excess all-cause mortality as well as mortality from cardiovascular diseases, respiratory diseases and cancers in the general population [2 - 5]. Furthermore, in people free of any respiratory symptoms or any known respiratory disease, Burney and Hooper have recently reported a low forced vital capacity (FVC) to be strongly correlated with higher all-cause mortality but not FEV1 and the FEV1/FVC ratio [6]. Moreover, in another recent study by Lee et al. [7], FVC and FEV1 improved mortality risk stratification based upon the Framingham risk equation in intermediate risk individuals. Knowledge of factors associated with low FVC in the general population is therefore important, and can assist risk evaluation and early identification and treatment of high risk individuals.

Few studies originating mostly from developed countries are available on the burden and risk factors for low FVC, also known as restrictive pattern. Across these studies, the prevalence of restrictive pattern in the general population ranged from $5.4 \%$ to $10.9 \%$ in US [8 - 10], to $74 \%$ in Aboriginal Australians [11]. These studies have also revealed many risk factors for restrictive pattern including high cardio-thoracic index, paralysis, diabetes mellitus and cardiovascular diseases (CVD) in the general population [9, 10]; and abdominal obesity, physical impairment, cognitive impairment and kypho-scoliosis in the elderly population [3].

The aim of the present study was to assess the prevalence of restrictive pattern (low FVC in the absence of airway obstruction) and investigate the determinants among adults in the general population from a major sub-Saharan African City.

\section{MATERIALS AND METHODS}

\section{Study Design and Participants}

This was a cross-sectional population-based survey conducted between December 2013 and April 2014 among adults (19 years of age and above) in Yaounde, the Capital City of Cameroon. Participants were recruited during a population-based survey aiming to quantify the burden of the commonest non-communicable respiratory diseases in Yaounde city. The sampling methods and selection of participants have been described in detail previously [12]. In brief, we used multilevel stratified sampling method to include participants in the current study. We firstly selected 16 enumeration areas (EA) out of the 2000 EAs of Yaounde city. In each enumeration area, we followed the itinerary of the national vaccination campaigns and then we used systematic sampling method to include participants in the study. About every one participant in two was selected for spirometry purpose (and if the spirometry was judged uninterpretable by the field workers, they included the next participant). Were excluded from the survey all participants with any of the following conditions: active tuberculosis, recent pneumonia, physical or mental inability to perform spirometry. Of the 1499 participants selected via multilevel stratified sampling across the seven administrative districts of Yaounde, to undergo spirometry tests during the survey, 212 (14.1\%) participants had completely uninterpretable spirometry (lack of reproducibility and incorrect maneuvers); $236(18.3 \%)$ of the remaining 1287 participants had reproducible curves but inadequate end of test plateau. Of the 1051 participants left, 48 (4.7\%) had airway obstruction (FEV1/FCV $<$ lower limit of normal [LLN]) and were therefore excluded from the analysis.

\section{Data Collection}

Data were collected by purposefully trained final year undergraduate medical students. A pre-tested questionnaire inspired by other questionnaires used in international surveys [13, 14], was used for data collection. The questionnaire was completed during face-to-face interview with consenting participants. Data were collected on the following: 1) socio-demographic details including age, sex and education; 2) exposure to tobacco which was assessed using a series of questions on tobacco use and participants classified as non-smokers (for those who never smoked, or had smoked less than 20 packs in their lifetime), active smokers (for participants who had smoked more than 20 packs in their lifetime, or at least one cigarette per day), and ex-smokers (for participants who had stopped smoking since at least six months) [15]; 3) self-reported history of existing conditions including pulmonary tuberculosis, asthma, pneumonia, cardiovascular diseases, diabetes mellitus, hypertension and cerebrovascular accident ; 4) chronic respiratory signs including chronic cough and expectoration for more than three months per year, dyspnea which was classified into four stages based on the modified Medical Research Council (mMRC) scale [16]; 5) biomass exposure based on exposure to 
cooking fumes from various solid fuels, and participants who had used solid fuels for cooking purpose for at least six month were classified as having been exposed to biomass [15]; 6) Anthropometric measures including height to the nearest centimeter, which was measured with a stadiometer in a participant without shoes, in the upright position, and weight (in kilograms) which was measured with a CAMRY weight scale (CAMRY, Guangzhou, China).

\section{Spirometric Measurements}

Flow-volume curves were acquired following the American Thoracic Society/European Respiratory Society (ATS/ERS) 2005 recommendations [17]. Spirometric examinations used a turbine pneumotachograph (Spiro USB, Care fusion, Yorba Linda-USA) or a Fleisch pneumotachograph (Spirolyser SPL-10 USB, FIM-Medical, Lyon-France), following the international standards, and were performed by a trained technician. All curves were reviewed by an experienced chest physician. Spirometric measurements were performed in a participant at rest for at least 15 minutes, in a sitting position with the back straight, and the nose clipped to allow air flow only per mouth. The ATS/ERS acceptability and reproducibility criteria were applied [17]. All subjects who had an acceptable expiratory plateau were included. At least three tests were done by each participant to establish the FVC curve. Spirometric variables measured included: FEV1, FVC and the FEV1/FVC ratio. FEV1 and FVC values retained were the best out of the three tests which fulfilled the acceptability criteria (maximal difference below 5\% or $150 \mathrm{ml}$ ). Predicted values were estimated using the reference spirometric values derived from a black African population [18]. Restrictive pattern was defined by a FVC below the age, sex and height specific LLN (LLN-based restrictive pattern). Sensitivity analyses were also conducted using an alternative definition which was based on FVC $<80 \%$ of the predicted value (fixed cut-off based restrictive pattern). The severity of restrictive pattern was based on a modification of the classification by Pellegrino et al.: mild restriction for FEV1 $>70 \%$, moderate restriction for $50 \% \leq \mathrm{FEV} 1 \leq 70 \%$ and severe for FEV $1<50 \%[1]$. The study was approved by the Ethics Committee of the Regional delegation of Health of Center Region of Cameroon.

\section{Statistical Analysis}

Data analysis used the IBM-SPSS v.20 for Windows (IBM, Chicago, USA). Qualitative variables are presented as count and frequencies, and quantitative variables as mean and standard deviation (SD) or median and $25^{\text {th }}-75^{\text {th }}$ percentiles. Graphical plots and Shapiro-Wilk test were used to assess the normality of the quantitative variables. There was indication of departure from normal distribution for all the quantitative variables included in the analysis. Group comparisons used chi square test for qualitative variables, and Mann-Whitney U test for quantitative variables. Agestandardized prevalence was calculated using the Cameroon National population's age structure in 2010 as the standard population [19], and direct standardization methods. Logistic regression models were employed to investigate the determinants of restrictive pattern. Significant predictors in univariable analysis (based on a threshold $p<0.10$ ) were entered altogether in the same multivariable model and the significant ones retained as the final determinants. A p-value $<0.05$ was used to characterize statistically significant results.

\section{RESULTS}

\section{General Characteristics of the Study Population}

The general characteristics of the included participants are described in Table 1. Of the 1003 participants included, $514(51.2 \%)$ were women. The mean age (SD) was $33.7(12.1)$ years and $44(4.4 \%)$ participants were aged 60 years and above. Women were less educated than men with $66.2 \%$ vs. $58.3 \%$ having achieved at most secondary school level education $(\mathrm{p}<0.001)$. Compared with women, men were more likely to be current smokers $(16 \%$ vs. $2.3 \%, \mathrm{p}<0.001)$, and as expected women were more likely to have been exposed to biomass than men $(8.4 \% v s .7 \%$, p $<0.001)$. With the exception of dyspnea which was more frequent in women than men $(31.7 \%$ vs. $18.4 \%, \mathrm{p}<0.001)$, chronic respiratory symptoms were equally distributed between men and women. The mean predicted FVC (SD) was 96.98\% (18.51\%) overall and the predicted value did not differ between men and women. Predicted FEV1 was also similar between men and women $(98.52 \%$ vs. $96.77 \%, \mathrm{p}=0.336)$.

Table 1. General characteristics of study population.

\begin{tabular}{|l|c|c|c|c|}
\hline Characteristics & Overall, $\mathbf{n}=\mathbf{1 0 0 3}(\mathbf{\%})$ & Men, $\mathbf{n}=\mathbf{4 8 9}(\mathbf{\%})$ & Women, $\mathbf{n}=\mathbf{5 1 4}(\mathbf{\%})$ & $\mathbf{p}$-value \\
\hline Age, years & & & & \\
\hline Mean (SD) & $33.7(12.1)$ & $33.5(12.3)$ & $34.0(11.8)$ & 0.237 \\
\hline Median $\left(25^{\text {th }}-75^{\text {th }}\right.$ percentiles) & $30(24-41)$ & $29(24-40)$ & $30(25-41)$ & \\
\hline
\end{tabular}




\begin{tabular}{|c|c|c|c|c|}
\hline Characteristics & Overall, $n=1003(\%)$ & Men, $n=489(\%)$ & Women, $n=514(\%)$ & p-value \\
\hline \multicolumn{5}{|l|}{ Age group, years } \\
\hline 19-39 & $730(72.8)$ & $364(74.4)$ & $366(71.2)$ & 0.231 \\
\hline $40-59$ & $229(22.8)$ & $101(20.7)$ & $128(24.9)$ & \\
\hline$\geq 60$ & $44(4.4)$ & $24(4.9)$ & $20(3.9)$ & \\
\hline \multicolumn{5}{|l|}{ Education } \\
\hline$\leq$ secondary & $664(66.2)$ & $285(58.3)$ & $379(73.7)$ & $<0.001$ \\
\hline Higher & $339(33.8)$ & $204(41.7)$ & $135(26.3)$ & \\
\hline \multicolumn{5}{|l|}{ Subject/bedrooms } \\
\hline$\leq 2$ & $561(56)$ & $307(62.8)$ & $254(49.5)$ & $<0.001$ \\
\hline$>2$ & $441(44)$ & $182(37.2)$ & $259(50.5)$ & \\
\hline \multicolumn{5}{|l|}{ Tobacco smoking } \\
\hline Current smoker & $90(9)$ & $78(16)$ & $12(2.3)$ & $<0.001$ \\
\hline Ex-smokers & $64(6.4)$ & $57(11.7)$ & $7(1.4)$ & \\
\hline Non smokers & $845(84.6)$ & $353(72.3)$ & $492(96.3)$ & \\
\hline \multicolumn{5}{|l|}{ Cooking fuel } \\
\hline Biomass & 76/982 (7.7) & $33 / 473(7)$ & $43 / 509(8.4)$ & $<0.001$ \\
\hline Mixed & $454 / 982(46.2)$ & $183 / 473(38.7)$ & $271 / 509(53.2)$ & \\
\hline Clean & 452/982 (46) & $257 / 473(54.3)$ & $195 / 509(38.3)$ & \\
\hline \multicolumn{5}{|l|}{ Past history of tuberculosis } \\
\hline Yes & $18(1.8)$ & $9(1.8)$ & $9(1.8)$ & 0.915 \\
\hline No & $985(98.2)$ & $480(98.2)$ & $505(98.2)$ & \\
\hline \multicolumn{5}{|l|}{ Past history of pneumonia } \\
\hline Yes & $28(2.8)$ & $17(3.5)$ & $11(2.1)$ & 0.199 \\
\hline No & $975(97.2)$ & $472(96.5)$ & $503(97.9)$ & \\
\hline \multicolumn{5}{|l|}{ Self-reported asthma } \\
\hline Yes & $23(2.3)$ & $7(1.4)$ & $16(3.1)$ & 0.075 \\
\hline No & $980(97.7)$ & $482(98.6)$ & $498(96.9)$ & \\
\hline \multicolumn{5}{|l|}{ History of stroke } \\
\hline Yes & $4(0.4)$ & $3(0.6)$ & $1(0.2)$ & 0.362 \\
\hline No & $999(99.6)$ & $486(99.4)$ & $513(99.8)$ & \\
\hline \multicolumn{5}{|c|}{ Self-reported diabetes mellitus } \\
\hline Yes & $12(1.2)$ & $6(1.2)$ & $6(1.2)$ & 0.931 \\
\hline No & $991(98.8)$ & $483(98.8)$ & $508(98.8)$ & \\
\hline \multicolumn{5}{|l|}{ Self-reported hypertension } \\
\hline Yes & $40(4)$ & $15(3.1)$ & $25(4.9)$ & 0.146 \\
\hline No & $963(96)$ & $474(96.9)$ & $489(95.1)$ & \\
\hline \multicolumn{5}{|l|}{ History of cardiac disease } \\
\hline Yes & $14(1.4)$ & $9(1.8)$ & $5(1)$ & 0.242 \\
\hline No & 989 (98.6) & $480(98.2)$ & $509(99)$ & \\
\hline \multicolumn{5}{|c|}{ Self-reported HIV infection } \\
\hline Yes & $7(0.7)$ & $3(0.6)$ & $4(0.8)$ & $<0.001$ \\
\hline No & $787(78.5)$ & $358(73.2)$ & $429(83.5)$ & \\
\hline Don't know & $209(20.8)$ & $128(26.2)$ & $81(38.8)$ & \\
\hline \multicolumn{5}{|l|}{ Respiratory symptoms } \\
\hline Chronic cough & $22(2.2)$ & $10(2)$ & $12(2.3)$ & 0.754 \\
\hline Chronic expectoration & $8(0.8)$ & $4(0.8)$ & $4(0.8)$ & $>0.999$ \\
\hline Recent wheezing & $24(2.4)$ & $11(2.2)$ & $13(2.5)$ & 0.772 \\
\hline Dyspnea & $253(25.2)$ & $90(18.4)$ & $163(31.7)$ & $<0.001$ \\
\hline Any symptoms & $271(27)$ & $98(20)$ & $173(33.7)$ & $<0.001$ \\
\hline $\mathrm{BMI}, \mathrm{Kg} / \mathrm{m}^{2}$, Mean (SD) & $26.1(5.3)$ & $25.4(4.3)$ & $27.4(5.9)$ & $<0.001$ \\
\hline \multicolumn{5}{|l|}{ FEV1 } \\
\hline Mean (SD), L & $3.08(0.85)$ & $3.59(0.82)$ & $2.60(0.54)$ & $<0.001$ \\
\hline$\%$ predicted $(\mathrm{SD})$ & $97.63(18.56)$ & $98.52(19.23)$ & $96.77(17.87)$ & 0.144 \\
\hline $\mathrm{FVC}$ & & & & \\
\hline
\end{tabular}


(Table प) contd.....

\begin{tabular}{|c|c|c|c|c|}
\hline Characteristics & Overall, $n=1003(\%)$ & Men, $n=489(\%)$ & Women, $n=514(\%)$ & p-value \\
\hline Mean (SD), L & $3.56(0.97)$ & $4.14(0.92)$ & $3.0(0.63)$ & $<0.001$ \\
\hline$\%$ predicted (SD) & $96.98(18.51)$ & $96.57(18.86)$ & $97.36(18.19)$ & 0.336 \\
\hline FEV1/FVC & $0.87(0.05)$ & $0.87(0.05)$ & $0.87(0.05)$ & 0.813 \\
\hline
\end{tabular}

SD, standard deviation; TB, tuberculosis; BMI, body mass index; FEV1, forced expiratory volume in 1s; FVC, forced vital capacity.

\section{Prevalence and Severity of Restrictive Pattern}

A total of 189 participants had a FVC < LLN; therefore, the crude prevalence of LLN-based restrictive pattern was $18.8 \%$ (95\% confidence interval [CI] 16.6-21.2). The age-standardized prevalence was $20.3 \%(17.8-22.2 \%)$. LLNbased restrictive pattern was mild in 148 (78.3\%) participants, moderate in $35(18.5 \%)$ and severe in $6(3.2 \%)$ participants. Furthermore, $127(67.2 \%)$ of participants with LLN-based restrictive pattern had a FEV1 $<80 \%$ of the predicted value. Based on a FVC $<80 \%, 180$ participants had a low FVC; therefore the prevalence of fixed cut-off based restrictive pattern was $15 \%$ (95\%CI: $13.0-17.2 \%)$.

\section{Determinants of Restrictive Pattern}

Univariable associations of baseline characteristics with LLN-based restrictive pattern are shown in Table 2. Participants with restrictive pattern were older $(37.2 \mathrm{vs} .32 .1$ years, $\mathrm{p}<0.001)$ and less educated (secondary school education or less: $72.5 \%$ vs. $64.7 \%, \mathrm{p}=0.043$ ). Other univariable correlates of restrictive pattern included a history of pulmonary tuberculosis [odds ratio $(95 \% \mathrm{CI}): 4.47(1.75-11.43), \mathrm{p}=0,002]$, history of heart disease [5.95 (2.04-17.38), $\mathrm{p}=0.001]$, exposure to biomass [1.98 (1.14-3.45), $\mathrm{p}=0.015)]$, chronic cough [2.53 (1.04-6.11), $\mathrm{p}=0.040]$, dyspnea stage 3 and 4 [2.02 (1.05-3.88), $\mathrm{p}=0.031$ ], and body mass index (BMI) $<18.5 \mathrm{~kg} / \mathrm{m}^{2}$ [5.32 (1.40-20.21), $\left.\mathrm{p}=0.014\right]$. Univariable determinants were similar for the outcome of fixed cut-off based restrictive pattern, with the exception of exposure to biomass for which the association was borderline (Supplementary Table 1).

Table 2. Univariable analysis of factors associated to restrictive pattern by FVC $<$ LLN and FEV1/FVC $\geq$ LLN.

\begin{tabular}{|c|c|c|c|c|}
\hline Determinants & $\begin{array}{l}\text { Restrictive pattern } \\
\mathrm{N}=189(\%)\end{array}$ & $\begin{array}{l}\text { Normal FVC } \\
\mathrm{N}=814(\%)\end{array}$ & Crude odds ratio $(95 \% \mathrm{CI})$ & p-value \\
\hline \multicolumn{5}{|l|}{ Gender } \\
\hline Male & $92(48.7)$ & $397(48.8)$ & $1.00(0.73-1.37)$ & 0.981 \\
\hline Female & $97(51.3)$ & $417(51.2)$ & 1 & \\
\hline Age, mean (SD), years & $37.2(14.5)$ & $32.1(11.3)$ & $1.03(1.02-1.04)$ & $<0.001$ \\
\hline \multicolumn{5}{|l|}{ Age group, years } \\
\hline $19-39$ & $123(65.1)$ & $607(74.6)$ & 1 & \\
\hline $40-59$ & $47(24.9)$ & $182(22.4)$ & $1.27(0.88-1.85)$ & 0.205 \\
\hline$\geq 60$ & $19(10,1)$ & $25(3.1)$ & $3.75(2.00-7.02)$ & $<0.001$ \\
\hline \multicolumn{5}{|l|}{ Ethnic group } \\
\hline Bantou & $174(92.1)$ & $771(94.7)$ & $0.63(0.23-1.78)$ & 0.384 \\
\hline Fulani & $10(5.3)$ & $29(3.6)$ & $0.97(0.28-3.37)$ & 0.956 \\
\hline Sudanese & $5(2.6)$ & $14(1.7)$ & 1 & \\
\hline \multicolumn{5}{|l|}{ Education } \\
\hline$\leq$ secondary & $137(72.5)$ & $527(64.7)$ & $1.44(1.01-2.04)$ & 0.043 \\
\hline Higher & $52(27.5)$ & $287(35.3)$ & 1 & \\
\hline \multicolumn{5}{|l|}{ Subject/bedrooms } \\
\hline$\leq 2$ & $108(57.1)$ & $453 / 813(55.7)$ & $1.06(0.77-1.46)$ & 0.723 \\
\hline$>2$ & $81(42.9)$ & $360 / 813(44.3)$ & 1 & \\
\hline \multicolumn{5}{|l|}{ Tobacco smoking } \\
\hline Current smoker & $19(10.1)$ & $71 / 810(8.8)$ & $1.16(0.68-1.99)$ & 0.579 \\
\hline Ex-smokers & $12(6.3)$ & $52 / 810(6.4)$ & $1.00(0.52-1.92)$ & 0.992 \\
\hline Non smokers & $158(83.6)$ & $687 / 810(84.8)$ & 1 & \\
\hline \multicolumn{5}{|l|}{ Cooking fuel } \\
\hline Biomass & $22 / 186(46.8)$ & $54 / 796(6.8)$ & $1.98(1.14-3.45)$ & 0.015 \\
\hline Mixed & $87 / 186(46.8)$ & $367 / 796(46.1)$ & $1.15(0.82-1.62)$ & 0.406 \\
\hline
\end{tabular}




\begin{tabular}{|c|c|c|c|c|}
\hline Determinants & $\begin{array}{l}\text { Restrictive pattern } \\
\mathrm{N}=189(\%)\end{array}$ & $\begin{array}{l}\text { Normal FVC } \\
\mathrm{N}=814(\%)\end{array}$ & Crude odds ratio $(95 \% \mathrm{CI})$ & p-value \\
\hline Clean & $77 / 186(41.1)$ & $796 / 796(47.1)$ & 1 & \\
\hline \multicolumn{5}{|l|}{ Past history of TB } \\
\hline Yes & $9(4.8)$ & $9(1.1)$ & $4.47(1.75-11.43)$ & 0.002 \\
\hline No & $180(95.2)$ & 805 (98.9) & 1 & \\
\hline \multicolumn{5}{|l|}{ Past history of pneumonia } \\
\hline Yes & $7(3.7)$ & $21(2.6)$ & $1.45(0.61-3.47)$ & 0.398 \\
\hline No & $182(96.3)$ & $793(97.4)$ & & \\
\hline \multicolumn{5}{|l|}{ Self-reported asthma } \\
\hline Yes & $3(1.6)$ & $20(2.5)$ & $0.64(0.19-2.18)$ & 0.475 \\
\hline No & $186(98.4)$ & $794(97.5)$ & 1 & \\
\hline \multicolumn{5}{|l|}{ History of stroke } \\
\hline Yes & $2(1.1)$ & $2(0.2)$ & $4.34(0.61-31.03)$ & 0.143 \\
\hline No & $187(98.9)$ & $812(00.8)$ & 1 & \\
\hline \multicolumn{5}{|c|}{ Self-reported diabetes mellitus } \\
\hline Yes & $4(2.1)$ & $8(1.0)$ & $2.19(0.65-7.31)$ & 0.208 \\
\hline No & $185(97.9)$ & $806(99.0)$ & 1 & \\
\hline \multicolumn{5}{|l|}{ Self-reported hypertension } \\
\hline Yes & $10(5.3)$ & $30(3.7)$ & $1.46(0.71-3.04)$ & 0.312 \\
\hline No & $179(94.7)$ & $784(96.3)$ & 1 & \\
\hline \multicolumn{5}{|l|}{ History of heart disease } \\
\hline Yes & $8(4.2)$ & $6(0.7)$ & $5.95(2.04-17.37)$ & 0.001 \\
\hline No & $181(95.8)$ & $808(99.3)$ & 1 & \\
\hline \multicolumn{5}{|l|}{ Self-reported HIV infection } \\
\hline Yes & $1(0.5)$ & $6(0.7)$ & $0.71(0.09-5.97)$ & 0.756 \\
\hline No & $149(78.8)$ & $638(78.4)$ & 1 & \\
\hline Don't know & $39(20.6)$ & $170(20.9)$ & $0.98(0.66-1.45)$ & 0.929 \\
\hline \multicolumn{5}{|l|}{ Respiratory symptoms } \\
\hline Chronic cough & $8(4.2)$ & $14(1.7)$ & $2.53(1.04-6.11)$ & 0.040 \\
\hline Chronic expectoration & $2(1.1)$ & $6(0.7)$ & $1.44(0.29-7.19)$ & 0.657 \\
\hline Recent wheezing & $5(2.6)$ & $19(2.3)$ & $1.14(0.42-3.09)$ & 0.801 \\
\hline Dyspnea & $59(31.2)$ & $194(23.8)$ & $1.45(1.03-2.05)$ & 0.035 \\
\hline mMRC dyspnea $>2$ & $14(7.4)$ & $31(3.8)$ & $2.02(1.05-3.88)$ & 0.031 \\
\hline Any respiratory symptoms & $62(32.8)$ & $209(25.7)$ & $1.41(1.00-1.99)$ & 0.047 \\
\hline BMI, $\mathrm{Kg} / \mathrm{m}^{2}$, Mean (SD) & $26.6(6.7)$ & $26.4(4.9)$ & $1.01(0.98-1.04)$ & 0.618 \\
\hline \multicolumn{5}{|l|}{ BMI classes } \\
\hline Underweight & $5 / 188(2.7)$ & $4 / 812(0.5)$ & $5.32(1.40-20.21)$ & 0.014 \\
\hline Overweight & $46(24.5)$ & $264(32.5)$ & $0.74(0.50-1.09)$ & 0.131 \\
\hline Obese & $47(25)$ & $161(19.8)$ & $1.24(0.84-1.85)$ & 0.285 \\
\hline Normal & $90(47.9)$ & $383(47.2)$ & 1 & \\
\hline
\end{tabular}

LLN, lower limit of normal; FVC, forced vital capacity; FEV1, forced expiratory volume in 1s; SD, standard deviation; TB, tuberculosis; mMRC, modified Medical Research Council scale; BMI, body mass index.

In multivariable regression models, independent determinants of LLN-based restrictive pattern were age $\geq 60$ years [adjusted odds ratio $(95 \% \mathrm{CI}): 2.90(1.46-5.77), \mathrm{p}=0.002]$, history of pulmonary tuberculosis $[3.81(1.42-10.20), \mathrm{p}=$ $0.008]$, past history of heart disease [3.81 (1.20-12.12), $\mathrm{p}=0.024]$ and underweight [5.15 $(1.30-20.39), \mathrm{p}=0.020]$ (Table 3). The pattern of the associations was similar for fixed cut-off based restrictive pattern, although the association with prevalent heart disease was no longer significant [1.64 (0.45-5.94, $\mathrm{p}=0.450]$ (Supplementary Table 2).

Table 3. Multivariable logistic regression model for determinants of restrictive pattern by CVF $<$ LLN and FEV1/FVC $\geq$ LLN.

\begin{tabular}{|l|c|c|c|}
\hline Determinants & Adjusted odds ratio & 95\% confidence interval & p-value \\
\hline Male gender & 1.06 & $0.75-1.50$ \\
\hline Age group, years & & & 0.754 \\
\hline
\end{tabular}


(Table $\square$ ) contd.....

\begin{tabular}{|c|c|c|c|}
\hline Determinants & Adjusted odds ratio & $95 \%$ confidence interval & p-value \\
\hline $19-39$ & 1.00 (reference) & & \\
\hline $40-59$ & 1.16 & $0.76-1.76$ & 0.489 \\
\hline$\geq 60$ & 2.90 & $1.46-5.77$ & 0.002 \\
\hline Education $\leq$ secondary & 1.33 & $0.91-1.94$ & 0.118 \\
\hline \multicolumn{4}{|l|}{ Cooking fuel } \\
\hline Biomass & 1.70 & $0.94-3.09$ & 0.080 \\
\hline Mixed & 1.13 & $0.79-1.62$ & 0.497 \\
\hline Clean & 1.00 (reference) & & \\
\hline Past history of TB & 3.81 & $1.42-10.20$ & 0.008 \\
\hline History of cardiac disease & 3.81 & $1.20-12.12$ & 0.024 \\
\hline Chronic cough & 1.92 & $0.71-5.14$ & 0.197 \\
\hline mMRC dyspnea $>2$ & 1.50 & $0.72-3.14$ & 0.279 \\
\hline \multicolumn{4}{|l|}{ BMI classes } \\
\hline Underweight & 5.15 & $1.30-20.39$ & 0.020 \\
\hline Overweight & 0.70 & $0.47-1.06$ & 0.093 \\
\hline Obese & 0.95 & $0.61-1.51$ & 0.843 \\
\hline Normal & 1.00 (reference) & & \\
\hline
\end{tabular}

LLN, lower limit of normal; FVC, forced vital capacity; FEV1, forced expiratory volume in 1s,

TB, tuberculosis; mMRC, modified Medical Research Council scale; BMI, body mass index.

\section{DISCUSSION}

In this population of urban dwellers from a major sub-Saharan African city, we found that about one in five adults had a low FVC, which was essentially driven by advanced age, history of pulmonary tuberculosis, prevalent heart diseases and underweight. These findings were largely robust to changes in criteria for defining low FVC. Since loss of respiratory functions, and particularly low FVC is important determinant of mortality risk in the general population [2 $6,8,20]$, our findings indicate the importance of using the identified determinants to select from the general population, those who are more likely to be diagnosed with restrictive pattern, and to benefit from targeted risk factors control to mitigate the risk of adverse outcomes.

"Although to establish the diagnosis of lung restriction, a lung volume measurement is needed, we used the term restrictive spirometric pattern to design the population with a low FVC with a FEV1/FVC > lower limit of normal [LLN])" The prevalence of restrictive spirometric pattern in our study was higher than the $6.6 \%$ (fixed cut-off based) and 5.4\% (LLN-based) reported respectively by Mannino et al., and Kurth et al. in the general population in the USA, using data from the third National Nutrition and Health Examination Survey [8, 10]. Similarly, Scarlata et al. found a prevalence of $10.9 \%$ for restrictive pattern among elderly people in the general population in Italy [3], which was by far lower than the $43.2 \%$ found among the 60 years old and above in our sample. However, prevalence of restrictive pattern as higher as $74 \%$ has been reported among Aboriginal population, while it is around $9.7 \%$ in non-Aboriginal Australians [11]. In the study by Mannino et al. comprising people age 40 years and above from 14 sites across different continents who took part in the Burden of Obstructive Lung Disease (BOLD) study, the prevalence of restrictive pattern defined by a ratio $\mathrm{FEV} 1 / \mathrm{FVC} \geq 70 \%$ and a $\mathrm{FVC}<80 \%$ varied from $6.1 \%$ in Sydney (Australia) to $29.3 \%$ in Cape Town (South Africa) and $45.9 \%$ in Manilla (Philippines) [21]. Soriano et al. also found a point prevalence of $12.7 \%$ in subjects aged 40 years and above in Spain [22]. In the $\geq 40$ years of age particpants in our study, the prevalence of restrictive pattern was 24.2\% (LLN-based) and 20.1\% (fixed cut-off based), which is closer to the South African figures in BOLD [21]. Global variations in the prevalence of restrictive pattern can be explained by regional differences in the distribution of a number of factors including socio-economic conditions, prevalence of obesity and underweight, birth weight, and prevalence of restrictive lung diseases. However, that restrictive diseases are rather rare in the general population [23] suggests that they contribute less to the burden of restrictive pattern across published studies.

The prevalence of restrictive pattern was four times higher in the $\geq 60$ years age group in our sample compared with those in the lower age stratum, and after adjustment for potential extraneous factors. The increasing prevalence of restrictive pattern with increasing age was very well characterized in the study by Mannino et al. where restrictive pattern was 2 to 2.5 times more frequent among the 50 years old and above compared with less older participants [9]. This is likely explained by the combined effect of several phenomena occurring with ageing which include deformation 
of the axial skeleton, restrictive lung diseases and lung ageing.

History of tuberculosis was a significant determinant of restrictive pattern in our study. This has not been reported previously in studies conducted in western countries, likely due to the low incidence of tuberculosis in those settings. Restrictive functional sequels of tuberculosis are very common [24, 25], mostly reflecting the exent of the parenchymatous involvement duing pulmonary tuberculosis [26]. Prevalent heart disease was also an independent determinant of restriction in our study. This result has not been reported in other studies [9], but Kurth et al. found a significant association between pulmonary restriction and cardiovascular diseases including congestive heart failure, stroke and heart attacks [10]. Cardiovascular diseases, when complicated with left heart failure can lead to pulmonary oedema, which in turn can reduce the vital capacity. Furthermore, heart diseases are often associated with cardiomegaly and muscle deconditioning, which are both associated with decreasing vital capacity [2,9].

Obesity has been classically associated with functional restrictive lung involvments [27]. Considering that FVC is not in perfect agreement with the total lung capacity (TLC) which is used as gold standard to diagnose pulmonary restriction, it is possible that the non-association of obesity with restrictive pattern in our sample was a chance finding. Furthermore, the majority of obese participants in our sample had moderate obesity. However, underweight was associated with restrictive pattern, in line with the findings of the GOLD study [21]. These association could reflect some underlying conditions which are actually correlated with restrictive pattern. Furthermore, there are suggestions of an inverse relationship between birth weight (not assessed in our study) and lung funtions [28].

The non-association of respiratory symptoms with restrictive pattern in our multivariable analyses reflects the correlation of those symptoms with other significant predictors of restrictive pattern, such as pulmonary tuberculosis and heart diseases. Diabetes and hypertension which have been reported to be associated with restrictive pattern [21] were not confirmed in our sample. It is of note however that statuses for diabetes and hypertension were based on selfreport in a setting where under-diagnosis of those conditions is very common. The presence of a high number of undiagnosed diabetes and/or hypertension among those with negative history, which is very likely, can erase any true association.

The present study has some limitations. FVC alone is not sufficient to clinically diagnose pulmonary restriction, for which measurement of the TLC via plethysmography or gas dilution is required. While FVC has very good specificity and negative predictive value to diagnose pulmonary restriction, the sensitivity hardly crosses $75 \%$ [29 - 31]. However, measurement of TLC in community-based study is a very challenging undertaking, while FVC-diagnosed restrictive pattern has been reported to be correlated all-cause and cause-specific mortality [4, 6, 7, 9, 20]. Furthermore, it is possible that the high prevalence of restrictive pattern found in this study is related to a high proportion of false positive related to the definition of the restriction used. Also, the relatively frequent exposure to the biomass of the population studied can lead to the obstruction of the distal airways causing the decline in FVC. The study was cross-sectional; hence it is not possible to reliably establish the sequence of happening between outcome of interest and exposure to potential determinants. Otherwise, the exclusion of patients with incorrect spirometric maneuvers may have influenced the prevalence of restrictive pattern. Our study also has major strengths and in particular the large representative community based sample, which will improve the generalizability of our findings.

\section{CONCLUSION}

Restrictive pattern was very frequent in this city.

\section{CLINICAL IMPLICATIONS}

These results enhance the needs to increase the efforts to prevent and control tuberculosis, cardiovascular diseases and underweight in this setting.

\section{SUPPLEMENTARY MATERIAL}

Supplementary material is available on the publishers Website along with the published article.

\section{LIST OF ABBREVIATIONS}

$\begin{array}{lll}\text { ATS/ERS } & = & \text { American Thoracic Society/European Respiratory } \\ \text { BMI } & = & \text { Body Mass Index }\end{array}$




$\begin{array}{lll}\text { CI } & = & \text { Society } \\ \text { BOLD } & = & \text { Burden of Obstructive Lung Disease } \\ \text { CVD } & = & \text { Cardiovascular Disease } \\ \text { FEV1 } & = & \text { Forced Expiratory Volume in First Second } \\ \text { FVC } & = & \text { Low Forced Vital Capacity } \\ \text { mMRC } & = & \text { Modified Medical Research Council Scale } \\ \text { SD } & = & \text { Standard Deviation } \\ \text { VC } & = & \text { Vital Capacity }\end{array}$

\section{CONFLICT OF INTEREST}

The authors confirm that this article content has no conflict of interest.

\section{ACKNOWLEDGEMENTS}

Declared none.

\section{REFERENCES}

[1] Pellegrino R, Viegi G, Brusasco V, et al. Interpretative strategies for lung function tests. Eur Respir J 2005; 26(5): 948-68. [http://dx.doi.org/10.1183/09031936.05.00035205] [PMID: 16264058]

[2] Mannino DM, Buist AS, Petty TL, Enright PL, Redd SC. Lung function and mortality in the United States: data from the First National Health and Nutrition Examination Survey follow up study. Thorax 2003; 58(5): 388-93. [http://dx.doi.org/10.1136/thorax.58.5.388] [PMID: 12728157]

[3] Scarlata S, Pedone C, Fimognari FL, Bellia V, Forastiere F, Incalzi RA. Restrictive pulmonary dysfunction at spirometry and mortality in the elderly. Respir Med 2008; 102(9): 1349-54.

[http://dx.doi.org/10.1016/j.rmed.2008.02.021] [PMID: 18599282]

[4] Menezes AM, Pérez-Padilla R, Wehrmeister FC, et al. FEV1 is a better predictor of mortality than FVC: the PLATINO cohort study. PLoS One 2014; 9(10): e109732.

[http://dx.doi.org/10.1371/journal.pone.0109732] [PMID: 25285441]

[5] Sin DD, Wu L, Man SF. The relationship between reduced lung function and cardiovascular mortality: a population-based study and a systematic review of the literature. Chest 2005; 127(6): 1952-9. [http://dx.doi.org/10.1378/chest.127.6.1952] [PMID: 15947307]

[6] Burney PG, Hooper R. Forced vital capacity, airway obstruction and survival in a general population sample from the USA. Thorax 2011; 66(1): 49-54.

[http://dx.doi.org/10.1136/thx.2010.147041] [PMID: 20980245]

[7] Lee HM, Le H, Lee BT, Lopez VA, Wong ND. Forced vital capacity paired with Framingham Risk Score for prediction of all-cause mortality. Eur Respir J 2010; 36(5): 1002-6. [http://dx.doi.org/10.1183/09031936.00042410] [PMID: 20562119]

[8] Mannino DM, Ford ES, Redd SC. Obstructive and restrictive lung disease and functional limitation: data from the Third National Health and Nutrition Examination. J Intern Med 2003; 254(6): 540-7. [http://dx.doi.org/10.1111/j.1365-2796.2003.01211.x] [PMID: 14641794]

[9] Mannino DM, Holguin F, Pavlin BI, Ferdinands JM. Risk factors for prevalence of and mortality related to restriction on spirometry: findings from the First National Health and Nutrition Examination Survey and follow-up. Int J Tuberc Lung Dis 2005; 9(6): 613-21. [PMID: 15971387]

[10] Kurth L, Hnizdo E. Change in prevalence of restrictive lung impairment in the U.S. population and associated risk factors: the National Health and Nutrition Examination Survey (NHANES) 19881994 and 20072010. Multidiscip Respir Med 2015; $10(1): 7$. [http://dx.doi.org/10.1186/s40248-015-0003-6] [PMID: 25745559]

[11] Cooksley NA, Atkinson D, Marks GB, et al. Prevalence of airflow obstruction and reduced forced vital capacity in an Aboriginal Australian population: the cross-sectional BOLD study. Respirology 2015; 20(5): 766-74. [http://dx.doi.org/10.1111/resp.12482] [PMID: 25704620]

[12] Pefura-Yone EW, Kengne AP, Balkissou AD, et al. Prevalence of asthma and allergic rhinitis among adults in Yaounde, Cameroon. PLoS One $2015 ; 10(4)$ : e0123099.

[http://dx.doi.org/10.1371/journal.pone.0123099] [PMID: 25853516]

[13] Burney PG, Luczynska C, Chinn S, Jarvis D. The European Community Respiratory Health Survey. Eur Respir J 1994; 7(5): 954-60. [http://dx.doi.org/10.1183/09031936.94.07050954] [PMID: 8050554] 
[14] Asher MI, Keil U, Anderson HR, et al. International Study of Asthma and Allergies in Childhood (ISAAC): rationale and methods. Eur Respir J 1995; 8(3): 483-91. [http://dx.doi.org/10.1183/09031936.95.08030483] [PMID: 7789502]

[15] Buist AS, Vollmer WM, Sullivan SD, et al. The burden of obstructive lung disease initiative (BOLD): rationale and design. COPD 2005; 2(2): 277-83. [http://dx.doi.org/10.1081/COPD-57610] [PMID: 17136954]

[16] Mahler DA, Wells CK. Evaluation of clinical methods for rating dyspnea. Chest 1988; 93(3): 580-6. [http://dx.doi.org/10.1378/chest.93.3.580] [PMID: 3342669]

[17] Miller MR, Hankinson J, Brusasco V, et al. Standardisation of spirometry. Eur Respir J 2005; 26(2): 319-38 [http://dx.doi.org/10.1183/09031936.05.00034805] [PMID: 16055882]

[18] Musafiri S, van Meerbeeck JP, Musango L, et al. Spirometric reference values for an East-African population. Respiration 2013; 85(4): 297-304. [http://dx.doi.org/10.1159/000337256] [PMID: 22584423]

[19] Cameroon's National Institute of Statistics. Population of Cameroon: State and structure of the population. Available from: http://www.statistics-cameroon.org/downloads/Etat_et_structure_de_la_population.pdf. 2015 [Accessed 27 Mar];

[20] Guerra S, Sherrill DL, Venker C, Ceccato CM, Halonen M, Martinez FD. Morbidity and mortality associated with the restrictive spirometric pattern: a longitudinal study. Thorax 2010; 65(6): 499-504. [http://dx.doi.org/10.1136/thx.2009.126052] [PMID: 20522846]

[21] Mannino DM, McBurnie MA, Tan W, et al. Restricted spirometry in the burden of lung disease study. Int J Tuberc Lung Dis 2012; 16(10): $1405-11$.

[http://dx.doi.org/10.5588/ijtld.12.0054] [PMID: 22863565]

[22] Soriano JB, Miravitlles M, García-Río F, et al. Spirometrically-defined restrictive ventilatory defect: population variability and individual determinants. Prim Care Respir J 2012; 21(2): 187-93. [http://dx.doi.org/10.4104/pcrj.2012.00027] [PMID: 22430039]

[23] Demedts M, Wells AU, Antó JM, et al. Interstitial lung diseases: an epidemiological overview. Eur Respir J Suppl 2001; 32: 2s-16s. [PMID: 11816822]

[24] Hnizdo E, Singh T, Churchyard G. Chronic pulmonary function impairment caused by initial and recurrent pulmonary tuberculosis following treatment. Thorax 2000; 55(1): 32-8.

[http://dx.doi.org/10.1136/thorax.55.1.32] [PMID: 10607799]

[25] Pasipanodya JG, Miller TL, Vecino M, et al. Pulmonary impairment after tuberculosis. Chest 2007; 131(6): 1817-24. [http://dx.doi.org/10.1378/chest.06-2949] [PMID: 17400690]

[26] de Vallière S, Barker RD. Residual lung damage after completion of treatment for multidrug-resistant tuberculosis. Int J Tuberc Lung Dis 2004; 8(6): 767-71.

[PMID: 15182148]

[27] Melo LC, Silva MA, Calles AC. Obesity and lung function: a systematic review. Einstein (Sao Paulo) 2014; $12(1): 120-5$. [http://dx.doi.org/10.1590/S1679-45082014RW2691] [PMID: 24728258]

[28] Suresh S, Mamun AA, OCallaghan M, Sly PD. The impact of birth weight on peak lung function in young adults. Chest 2012; 142(6): 1603-10.

[http://dx.doi.org/10.1378/chest.11-2976] [PMID: 22539648]

[29] Venkateshiah SB, Ioachimescu OC, McCarthy K, Stoller JK. The utility of spirometry in diagnosing pulmonary restriction. Lung 2008; 186(1): 19-25. [http://dx.doi.org/10.1007/s00408-007-9052-8] [PMID: 17990034]

[30] Quadrelli S, Bosio M, Salvado A, Chertcoff J. Accuracy of spirometry in the diagnosis of pulmonary restriction. Medicina (B Aires) 2007; 67(6 Pt 2): 685-90.

[PMID: 18422058]

[31] Zielonka T, Kostera-Pruszczyk A, Ryniewicz B, Korczyński P, Szyluk B. How accurate is spirometry at predicting restrictive pulmonary impairment in children with myasthenia gravis. J Physiol Pharmacol 2006; 57(Suppl. 4): 409-16.

[PMID: 17072071]

(C) Pefura-Yone et al:; Licensee Bentham Open.

This is an open access article licensed under the terms of the Creative Commons Attribution-Non-Commercial 4.0 International Public License (CC BY-NC 4.0) (https://creativecommons.org/licenses/by-nc/4.0/legalcode), which permits unrestricted, non-commercial use, distribution and reproduction in any medium, provided the work is properly cited. 